\title{
Reference crop evapotranspiration derived from geo-stationary satellite imagery: a case study for the Fogera flood plain, NW-Ethiopia and the Jordan Valley, Jordan
}

\author{
H. A. R. de Bruin ${ }^{1}$, I. F. Trigo ${ }^{2,6}$, M. A. Jitan ${ }^{3}$, N. Temesgen Enku ${ }^{4}$, C. van der Tol ${ }^{5}$, and A. S. M. Gieske \\ ${ }^{1}$ Associate Professor Emeritus Wageningen University, freelance researcher, Bilthoven, The Netherlands \\ ${ }^{2}$ Instituto de Meteorologia, Lisbon, Portugal \\ ${ }^{3}$ NCARE, Department Water and Environment, Amman, Jordan \\ ${ }^{4}$ Department of water Resources Engineering, Bahir Dar University, Bahir Dar, Ethiopia \\ ${ }^{5}$ University of Twente, Faculty ITC, Enschede, The Netherlands \\ ${ }^{6}$ Instituto Dom Luiz, Lisbon, Portugal
}

Received: 25 June 2010 - Published in Hydrol. Earth Syst. Sci. Discuss.: 23 July 2010

Revised: 25 October 2010 - Accepted: 4 November 2010 - Published: 10 November 2010

\begin{abstract}
First results are shown of a project aiming to estimate daily values of reference crop evapotranspiration $\mathrm{ET}_{0}$ from geo-stationary satellite imagery. In particular, for Woreta, a site in the Ethiopian highland at an elevation of about $1800 \mathrm{~m}$, we tested a radiation-temperature based approximate formula proposed by Makkink (MAK), adopting $\mathrm{ET}_{0}$ evaluated with the version of the Penman-Monteith equation described in the FAO Irrigation and Drainage paper 56 as the most accurate estimate. More precisely we used the latter with measured daily solar radiation as input (denoted by PMFAO-Rs). Our data set for Woreta concerns a period where the surface was fully covered with short green non-stressed vegetation. Our project was carried out in the context of the Satellite Application Facility on Land Surface Analysis (LANDSAF) facility. Among others, the scope of LANDSAF is to increase benefit from the EUMETSAT Satellite Meteosat Second Generation (MSG). In this study we applied daily values of downward solar radiation at the surface obtained from the Spinning Enhanced Visible and Infrared Imager (SEVIRI) radiometer. In addition, air temperature at $2 \mathrm{~m}$ was obtained from 3-hourly forecasts provided by the European Centre for Medium-Range Weather Forecasts (ECMWF).

Both MAK and PMFAO-Rs contain the psychrometric "constant", which is proportional to air pressure, which, in turn, decreases with elevation. In order to test elevation effects we tested MAK and its LANDSAF input data for 2 sites in the Jordan Valley located about $250 \mathrm{~m}$ b.s.l.
\end{abstract}

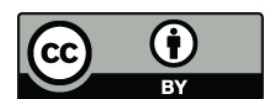

Correspondence to: H. A. R. de Bruin (hardb@xs4all.nl)
Except for a small underestimation of air temperature at the Ethiopian site at $1800 \mathrm{~m}$, the first results of our LANDSAF-ET $_{0}$ project are promising. If our approach to derive $\mathrm{ET}_{0}$ proves successfully, then the LANDSAF will be able to initiate nearly real time free distribution of $\mathrm{ET}_{0}$ for the full MSG disk.

\section{Introduction}

Nowadays the method proposed by Allen et al. (1998) to determine evaporative demands of agricultural crops has become generally recognized as the most accurate and has been adopted as a standard approach. It is a concept in which the reference evapotranspiration, $\mathrm{ET}_{0}$, is introduced and in which the water requirements of a particular crop ( $\left.\mathrm{ET}_{\text {crop }}\right)$ are obtained with

$\mathrm{ET}_{\text {crop }}=K_{\mathrm{c}} \mathrm{ET}_{0}$

where $K_{\mathrm{c}}$ is a crop factor. For a full description of this approach see Allen et al. (1998).

$\mathrm{ET}_{0}$ is the evapotranspiration $\left(\mathrm{mm} \mathrm{d}^{-1}\right)$ under the given meteorological conditions from a reference surface, notably, an extensive, hypothetical grass reference crop with specific characteristics. The methodology requires input data gathered over a horizontal extensive surface similar to the hypothetical extensive grass field. Although standard weather stations as specified by the World Meteorological Organization refer to similar grass fields, such stations are rare in semiarid regions. The reason is obvious: it is very difficult to maintain grass in the required conditions in the dry season.

Published by Copernicus Publications on behalf of the European Geosciences Union. 
As a consequence the number of weather stations fulfilling the requirements that the input parameters are gathered over well-watered grass is small in most semi-arid regions, while the density of weather stations is sparse anyway in most of semi-arid regions.

It is the objective of this study to present an alternative methodology to derive $\mathrm{ET}_{0}$ from geostationary satellite images and additional information provided by operational weather forecast models for irrigation advice purposes. In the methodology proposed here, $\mathrm{ET}_{0}$ relies essentially on daily values of downward solar flux at the surface obtained from the Spinning Enhanced Visible and Infrared Imager (SEVIRI) radiometer onboard Meteosat Second Generation (MSG), provided by the Satellite Application Facility on Land Surface Analysis (hereafter LANDSAF; see also Trigo et al., 2010). If the approach analyzed here to derive $\mathrm{ET}_{0}$ proves successfully, the LANDSAF will initiate the retrieval and distribution in near real time or off-line of that parameter from SEVIRI/MSG, as described below.

It should be stressed that the alternative method to be developed is not meant to replace the current FAOmethodology by Allen et al. (1998). In contrast, this approach is highly recommended and taken as standard reference for this study. But then the input data should be collected over well-watered grass or a similar surface.

The LANDSAF-ET ${ }_{0}$ activity is still under development, not at least because validation is needed under a wide range of environmental and climatic conditions. In this research note some first results of a case study for a location in Ethiopia will be presented. For this purpose we will use some data collected at Woreta in the Fogera flood plain near Lake Tana in NW Ethiopia, which has an elevation of about $1800 \mathrm{~m}$. In order to study elevation effects on $\mathrm{ET}_{0}$ we will use data gathered at two stations in the Jordan valley located about $250 \mathrm{~m}$ b.s.l. in addition.

\section{The FAO Penman-Monteith equation}

It is recalled that $\mathrm{ET}_{0}$ is the evapotranspiration under the given meteorological conditions from a hypothetical grass reference crop with specific characteristics. By definition this reference grass crop has a height of $0.12 \mathrm{~m}$, a fixed surface resistance of $70 \mathrm{~s} \mathrm{~m}^{-1}$ and an albedo of 0.23 . The reference surface closely resembles an extensive surface of green, well-watered grass of uniform height, actively growing and completely shading the ground. The fixed surface resistance of $70 \mathrm{~s} \mathrm{~m}^{-1}$ implies a moderately dry soil surface resulting from about a weekly irrigation frequency. Allen et al. (1998) provides guidelines on how to calculate $\mathrm{ET}_{0}$ from standard weather data. The methodology concerns an application of the Penman-Monteith equation (hereafter denoted as PMFAO) using the aforementioned surface resistance of $70 \mathrm{~s} \mathrm{~m}^{-1}$ and an aerodynamic resistance given by

$r_{\mathrm{a}}=\frac{208}{u_{2}}$ where $u_{2}$ is the wind speed at $2 \mathrm{~m}$.

This relation is derived from neutral logarithmic fluxprofile expressions for water vapor transfer using a roughness length for momentum $z_{0 \mathrm{~m}}=0.123 \mathrm{~h}$, a roughness length governing transfer of heat and vapor $z_{0 \mathrm{~h}}=0.1 z_{0 \mathrm{~m}}$ and a zero-plane displacement $d=2 / 3 h$, with vegetation height $h=0.12 \mathrm{~m}$. Furthermore, Eq. (2) implies that besides the wind speed, humidity and temperature data are collected at $2 \mathrm{~m}$ too.

For this hypothetical grass surface the Penman-Monteith model can be written as (Allen et al., 1998):

$\mathrm{ET}_{0}=\frac{0.408 \Delta\left(R_{\mathrm{n}}-G\right)+\gamma \frac{900}{T+273} u_{2}\left(e_{\mathrm{s}}-e_{\mathrm{a}}\right)}{\Delta+\gamma\left(1+0.34 u_{2}\right)}$

in which $R_{\mathrm{n}}$ is the net radiation at the crop surface $\left(\mathrm{MJ} \mathrm{m}^{-2} \mathrm{~d}^{-1}\right), G$ is soil heat flux density $\left(\mathrm{MJ} \mathrm{m}^{-2} \mathrm{day}^{-1}\right)$, assumed zero on daily bases, $T$ the mean daily air temperature at $2 \mathrm{~m}$ height $\left({ }^{\circ} \mathrm{C}\right), e_{\mathrm{S}}$ the saturation vapor pressure at air temperature $(\mathrm{kPa}), e_{\mathrm{a}}$ actual vapour pressure $(\mathrm{kPa}), \Delta$ the slope of the saturation water vapor pressure temperature curve $\left(\mathrm{kPa}^{\circ} \mathrm{C}^{-1}\right)$ and $\gamma$ is psychometric constant $\left(\mathrm{kPa}^{\circ} \mathrm{C}^{-1}\right)$. The latter is proportional to air pressure and is slightly $T$ dependent also. Note that $D \equiv e_{\mathrm{s}}-e_{\mathrm{a}}$ the saturation vapor pressure deficit $(\mathrm{kPa})$.

Dealing with daily mean values one should account for non-linearity effects. More or less implicitly, Allen et al. (1998) recommend solving for these effects by using the following equations:

$\overline{e_{\mathrm{s}}}=\frac{e^{0}\left(T_{\max }\right)+e^{0}\left(T_{\min }\right)}{2}$

and

$\overline{e_{\mathrm{a}}}=\frac{e^{0}\left(T_{\min }\right) \mathrm{RH}_{\max }+e^{0}\left(T_{\max }\right) \mathrm{RH}_{\min }}{2}$

where a bar means a 24 hourly average, $e^{0}(T)$ is the saturation water pressure $(\mathrm{kPa})$ at temperature $T, \mathrm{RH}$ is the relative humidity and the suffixes "max" and "min" indicate maximum and minimum value in a day. In general, $D$ determined from daily mean RH and $T$ is smaller than $D$ evaluated with $D=\overline{e_{\mathrm{s}}}-\overline{e_{\mathrm{a}}}$ using Eqs. (4) and (5). Moreover, it is recommended to use $\Delta$ at the mean daily temperature.

Net radiation is given by

$R_{\mathrm{n}}=(1-\alpha) R_{\mathrm{s}}-R_{\mathrm{nl}}$

in which $\alpha$ is the albedo (assumed to be 0.23 ), $R_{\mathrm{S}}$ the incoming short-wave radiation and $R_{\mathrm{nl}}$ the net long-wave radiation. Following Allen et al. (1998) the latter is approximated with

$$
\begin{aligned}
& R_{\mathrm{n} 1}=\sigma\left[\frac{T_{\max }^{4}+T_{\min }^{4}}{2}\right]\left(0.34-0.14 \sqrt{e_{\mathrm{a}}}\right) \\
& \left(1.35 \frac{R_{\mathrm{s}}}{R_{\mathrm{s} 0}}-0.35\right)
\end{aligned}
$$


where $\sigma$ is the Stefan-Boltzmann constant $\left(4.90310^{-9} \mathrm{MJ}\right.$ $\mathrm{K}^{-4} \mathrm{~m}^{-2}$ day $\left.^{-1}\right), T_{\min }$ and $T_{\max }$ are the absolute minimum and maximum temperature $(\mathrm{K})$ and $R_{\mathrm{S} 0}$ the clear-sky incoming solar radiation evaluated from the extraterrestrial radiation for daily period $R_{\mathrm{a}}$ :

$R_{\mathrm{s} 0}=\left(0.75+2 \times 10^{-5} z\right) R_{\mathrm{a}}$

with $z$ the station elevation above sea level in $\mathrm{m}$.

The physics behind expression (Eq. 7) is outside the scope of this research note.

\section{Approach}

The subject of this study concerns the evapotranspiration over a hypothetical grass reference crop with the characteristics described above. Because in the real world such surfaces are non-existing, it is difficult to verify experimentally any formula for $\mathrm{ET}_{0}$ and to develop an alternative satellite based method. Based on several lysimeter studies we are confident that PMFAO, with incoming short-wave radiation measured directly, is the most accurate $\mathrm{ET}_{0}$ estimate. This version of the Penman-Monteith equation will be denoted as PMFAORs. Our alternative method will be compared with PMFAORs.

On purpose, we do not adopt as "best" $\mathrm{ET}_{0}$ estimate PMFAO formula where net radiation is observed directly. The main reason is that net radiation depends on the actual surface temperature, by which it is affected by water stress. We will discuss this later.

So, the objective of this study is to derive a simplified $\mathrm{ET}_{0}$ formula requiring input data that can be retrieved from remotely sensed solar radiation, in particular those available from the LANDSAF, which compares well with PMFAO-Rs.

As early as 1957 Makkink showed that the evapotranspiration of well-watered short grass in the Netherlands can be estimated with a simple radiation based formula: that, in energy units reads, as:

$\lambda \mathrm{ET}=c_{1} \frac{\Delta}{\Delta+\gamma} R_{\mathrm{s}}+c_{2}$

where $\lambda$ is the latent heat of vaporization, $c_{1}(-)$ and $c_{2}$ $\left(\mathrm{W} \mathrm{m}^{-2}\right)$ are constants, ET the evapotranspiration of wellwatered grass. The other quantities are defined above. The units are $\mathrm{W} \mathrm{m}^{-2}$.

De Bruin (1987) showed that in "normal" Dutch summers when water stress is rare, the evapotranspiration of short grass at Cabauw (The Netherlands) can be estimated accurately with a simplified Makkink formula (hereafter denoted as MAK):

$\mathrm{ET}_{\mathrm{MAK}}=c_{\text {mak }} \frac{1}{\lambda} \frac{\Delta}{\Delta+\gamma} R_{\mathrm{S}}$

De Bruin (1987) reported that $c_{\mathrm{mak}}=0.65$. Moreover, he argued that the method is not applicable in the Dutch winter season. Later this was confirmed by Van Kraalingen and
Stol (1997), who found that $c_{\text {mak }}=0.63$ for the growing season in The Netherlands.

Jitan (2005) studied MAK and compared it with PMFAO and he estimated for the Jordan Valley (Dair Allah station) $c_{\mathrm{MAK}}=0.81$.

Stewart et al. (1999) and Watts et al. (2000) developed a methodology for calculating $\mathrm{ET}_{0}$ based on the Makkink approach using GOES data to estimate the solar radiation. Field measurement of water consumption for wheat and cotton in the Yaqui valley (Garatuza-Payan et al., 1998) showed good agreement with results obtained from Eq. (10). A useful product has been developed for northern Mexico (see Garatuza-Payan and Watts, 2003).

Schüttemeyer (2005) and Schüttemeyer et al. (2007) applied MAK derived from the (first generation) METEOSAT images successfully in Ghana (see also de Bruin et al., 2005). They used both ideas by Choudhury and de Bruin (1995) and a procedure to determine the solar radiation by Schillings et al. (2004).

Jacobs et al. (2004) applied daily solar radiation estimates derived from GOES imagery as input in the PenmanMonteith equation to estimate wetland evapotranspiration. Similarly, Bois et al. (2007) applied MSG-derived solar radiation to determine $\mathrm{ET}_{0}$. Recently, Sinclair and Pegram (2010) propose to use LANDSAF solar radiation in a numerical weather forecast model for $\mathrm{ET}_{0}$ estimations in South Africa.

Recently, Temesgen (2009) showed that $\mathrm{ET}_{0}$ evaluated with MAK performed well for two stations in the Fogera flood plain. Furthermore, Jitan $(2004,2005)$ applied MAK with a revised coefficient for stations in the Jordan Valley.

It should be stressed that experience shows that in arid conditions the Makkink formula tends to underestimate $\mathrm{ET}_{0}$ (Allen et al., 1998; Gavilán et al., 2008; Irmak et al., 2008). The authors are well aware of this feature. These conditions will also be considered in subsequent studies.

This case study for the fairly humid location in the Fogera flood plain is meant to show some first results of the LANDSAF-ET 0 project. The elevation of this region is about $1800 \mathrm{~m}$ a.s.l. (above sea level). In order to investigate elevation effects on $\mathrm{ET}_{0}$ (e.g. through the psychrometric constant $\gamma$ ) we will consider applications of our method to the Jordan Valley in Jordan also, which is located about $250 \mathrm{~m}$ b.s.l. Of course, other environmental differences between the two locations apart from elevation are relevant as well.

\section{Experimental}

The Fogera flood plain is located east of Lake Tana in North West Ethiopia, about $625 \mathrm{~km}$ from the capital Addis Ababa. The terrain is fairly flat.

The Fogera flood plain is frequently affected by floods. There have been floods recorded in the years of 1996, 1998, 1999, 2000, 2001, 2003 and 2006. The 1996 flood set a new 


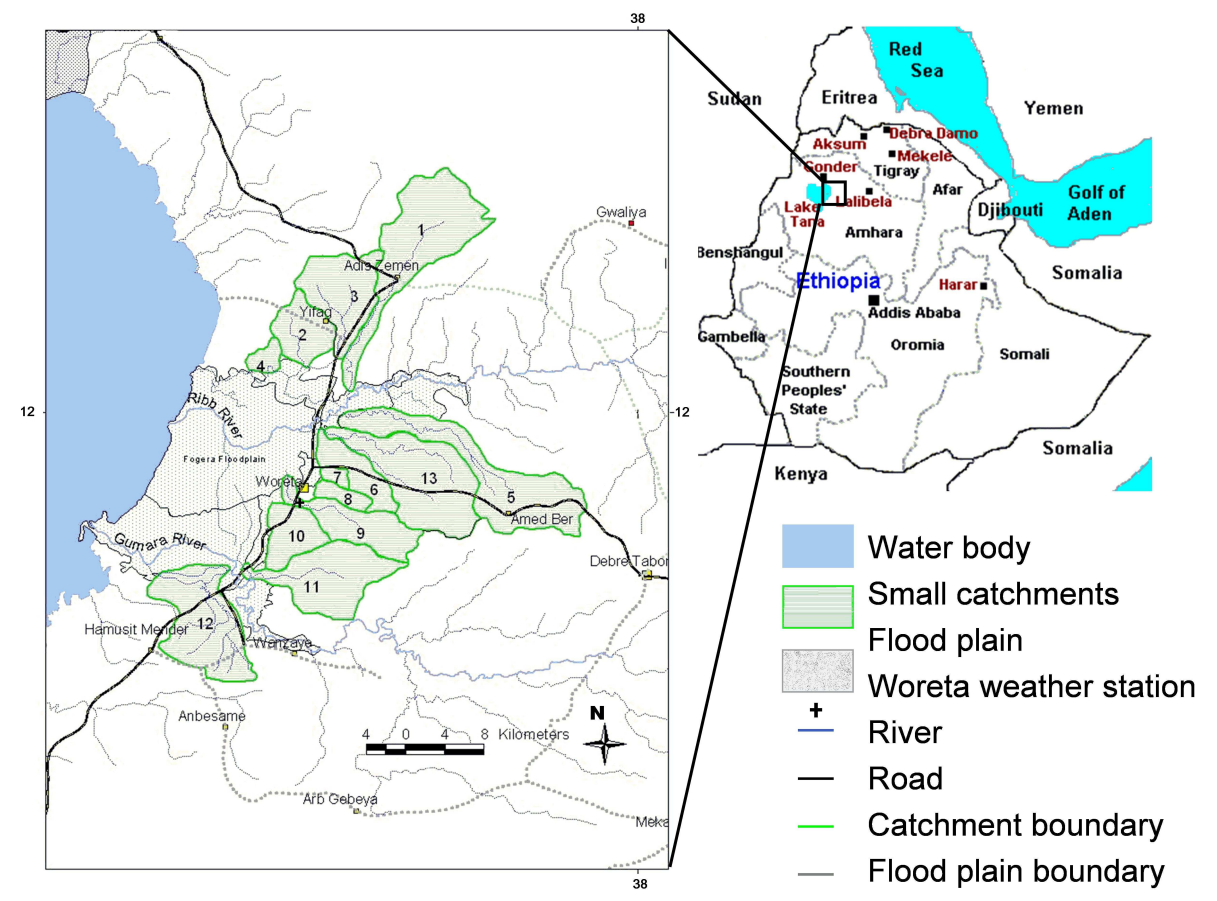

Fig. 1. Map of the Fogera flood plain.

record for flooded area, while 2006 flood was recorded with its long duration and damage. Heavy rain in that year caused rising of the lake level and overtopping of the rivers, and as a consequence, cattle was killed, and crops and thousands of houses were destroyed. In general, the dry season is from November through April, so the wet season is between May through September (Temesgen, 2009). The mean air pressure during the observation period was $82 \mathrm{kPa}$. A map of the flood plain is shown in Fig. 1.

In 2008 ITC installed an automatic weather station at Woreta, see Fig. 1. For the period July 2008 - early November 2008 daily data of air temperature and global radiation are available as well all input data required for PMFAO-Rs. The surface was short grass that during this period did not suffer water stress. We will also use some data gathered at Bahir Dar, a station of the national meteorological office. At this station solar radiation is not observed directly, but is estimated from measured sunshine duration. For more details see Temesgen (2009).

We will also use a set of micrometeorological data also gathered at two stations located in the Jordan Valley. The Jordan valley is Jordan's premier agricultural production area. The mild winter in the Valley, due to its below-sea level elevation $(-170$ in the north down to $-404 \mathrm{~m}$ near the Dead Sea), gives it great potential for the production of off-season fruits and vegetables. The area of the Jordan Rift Valley extends from the lake of Tabarieh in the North to the Red Sea in the South, passing through the Dead Sea. The north area of the Dead Sea is called the Jordan Valley, while the area south of it is called southern Ghors, and Wadi Arabah. Rainfall in Jordan Valley varies from $100 \mathrm{~mm}$ in the South to about $400 \mathrm{~mm}$ in the North. For more information about this irrigation region see Fardous (1983), Shatanawi et al. (1986, 1994), Ghawi and Shatanawi (1986) and Mazahreh (2001). Irrigation agriculture has been practiced in the Jordan Valley since the dawn of human civilization. The formal development of irrigated agriculture started in the early 1950s in the Zarqa Triangle. In those days scientific agricultural research institutions were established, which lead, among others, to the establishment of The National Center for Agricultural Research and Extension (NCARE) previously called NCARTT.

In the Jordan Valleys three agro-meteorological stations were installed by NCARE in the year 2000, and the data are published at the web site www.ncare.gov.jo/imis. Among other variables all input data for PMFAO-Rs are observed operationally. In this study we use data collated at Dair Allah and Karameh. The mean air pressure in the region is about $104 \mathrm{kPa}$. The Dair Allah station is located at a latitude of $32^{\circ} 13^{\prime} \mathrm{E}$ and longitude of $35^{\circ} 37^{\prime} \mathrm{N}$, and an altitude of $-224 \mathrm{~m}$ b.s.l. The annual precipitation is about $277 \mathrm{~mm}$ a year. This Karameh station was established in the year 1983 , it is located at a latitude of $32^{\circ} 12^{\prime} \mathrm{N}$ and longitude of $35^{\circ} 37^{\prime} \mathrm{E}$, and an altitude of about -240 b.s.l. The annual precipitation in this area is about $155 \mathrm{~mm}$. For the locations of the stations see Fig. 2.

For this research note we used the operationally available incoming solar radiation $R_{\mathrm{S}}$ or Daily Down-welling Surface 




Fig. 2. Map of the two Jordan stations.

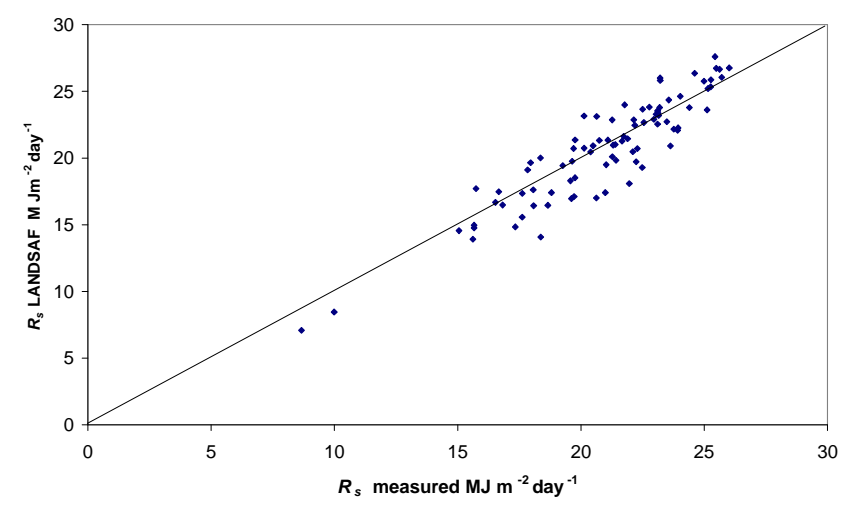

Fig. 3. Comparison between measured daily incoming solar radiation at Woreta with the corresponding LANDSAF values. Linear regression: slope 0.99 , correlation coefficient 0.91 .

Short-wave Radiation Flux (DSSF) provided by the LANDSAF (Trigo et al., 2010). Daily $R_{\mathrm{S}}$ values, accumulated between 00:00 and 24:00 UTC, are obtained from instantaneous flux estimated every 30-min from SEVIRI/MSG data. The values are estimated at the original pixel resolution of $3 \mathrm{~km}$ at the sub-satellite point (Geiger et al., 2008). For details see http://landsaf.meteo.pt/products/prods.jsp.

Air temperature at $2 \mathrm{~m}(\mathrm{~T} 2 \mathrm{~m})$ is obtained from forecasts provided by the European Centre for Medium-range Weather Forecasts (ECMWF) model. The initial 3-hourly $\mathrm{T} 2 \mathrm{~m}$ forecasts (steps between $12 \mathrm{~h}$ and $36 \mathrm{~h}$ ) at a resolution of about $25 \mathrm{~km}$, are linearly interpolated in time to hourly, and bilinearly interpolated in space to the SEVIRI/MSG resolution. The $2 \mathrm{~m}$ temperature values undergo a further adjustment to

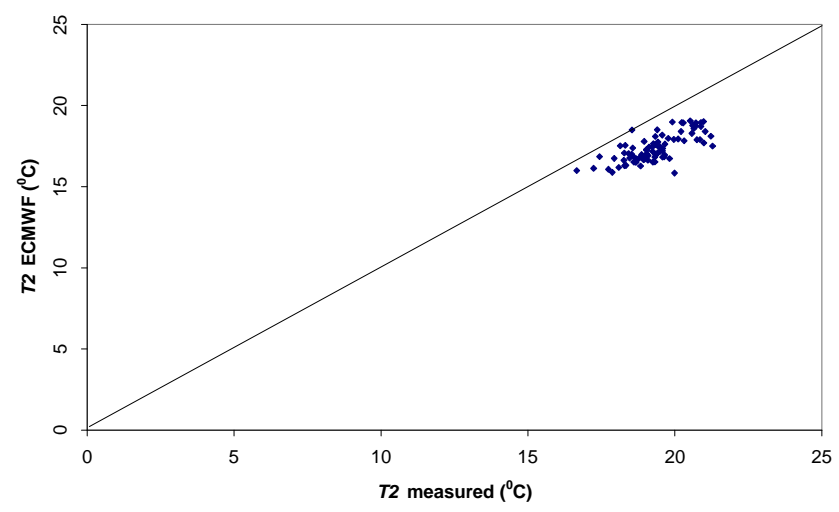

Fig. 4. Comparison between measured air temperature at Woreta with the corresponding ECMWF values. Linear regression: due to the small temperature range not applicable.

correct differences between ECMWF mode surface orography and SEVIRI pixel altitude, using a constant lapse rate of $0.0067^{\circ} \mathrm{C} \mathrm{m}^{-1}$.

\section{Results}

For the period 1 July-8 November 2008 we compared the daily LANDSAF incoming solar radiation and ECMWF air temperatures estimates with the corresponding values measured at Woreta. The results are shown in Figs. 3 and 4. It is seen that the the LANDSAF estimates of $R_{\mathrm{S}}$ compare fairly well ( $R=0.91$, slope of linear regression 0.99 ), but the ECMWF air temperatures are systematically too low (about 


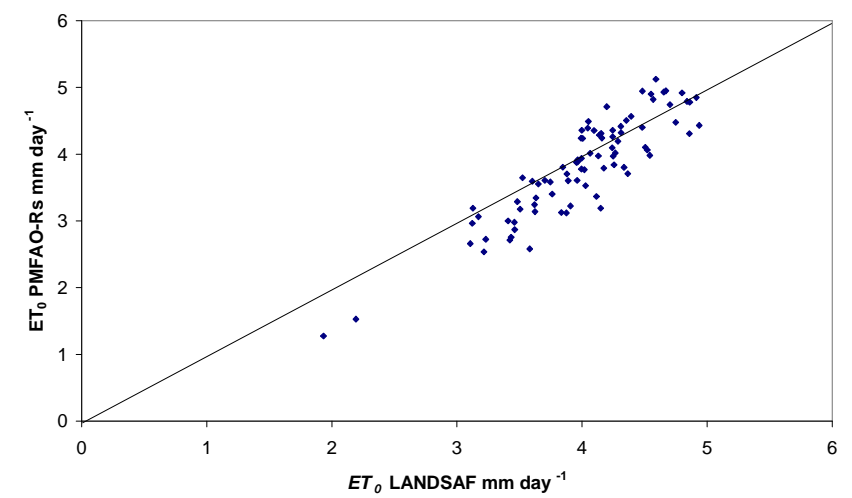

Fig. 5. ET $_{0}$ evaluated with PMFAO-Rs and the MAK-LANDSAF method. Not corrected for underestimation of $T$ by LANDSAFECMWF. Linear regression: slope 0.96, correlation coefficient 0.88 .

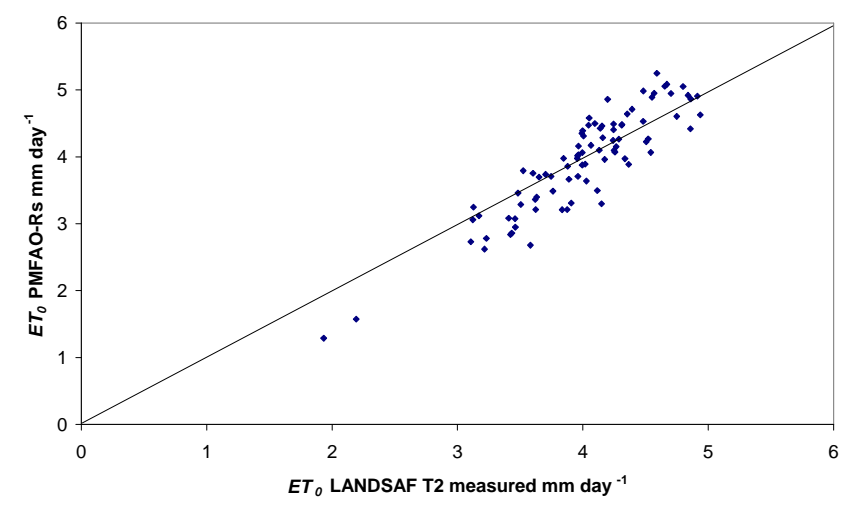

Fig. 6. As Fig. 5, but with locally measured temperature. Linear regression: slope 0.99 , correlation coefficient 0.88 .

$2{ }^{\circ} \mathrm{C}$ ). As mentioned in the previous section, ECMWF temperature is adjusted by means of a constant lapse rate to take into account the elevation differences between ECMWF model $(1956 \mathrm{~m})$ and actual station height $(1811 \mathrm{~m})$, leading to a correction of $+0.95^{\circ} \mathrm{C}$. In Fig. 5, daily $\mathrm{ET}_{0}$ evaluated with PMFAO-Rs for Woreta is compared with $\mathrm{ET}_{0}$ determined with MAK using MSG LANDSAF incoming solar radiation and ECMWF air temperature. Apparently, orographic adjustment was not enough to reduce the systematic underestimation of $T$ (Fig. 4) which results in some underestimation of $\mathrm{ET}_{0}$. This is confirmed in Fig. 6, where measured $T$ is used instead of the ECMWF $T$ values.

In order to show the sensitivity of $\mathrm{ET}_{0}$ to solar radiation we plotted in Fig. 7 ET $_{0}$ evaluated with PMFAO using the same locally measured input data, except solar radiation at Woreta and at Bahir Dar about $40 \mathrm{~km}$ apart. In Bahir Dar solar radiation is determined from the measured sunshine duration, whereas at Woreta $R_{\mathrm{S}}$ is measured directly. Temesgen (2009) showed that the other input parameters for PMFAO of these

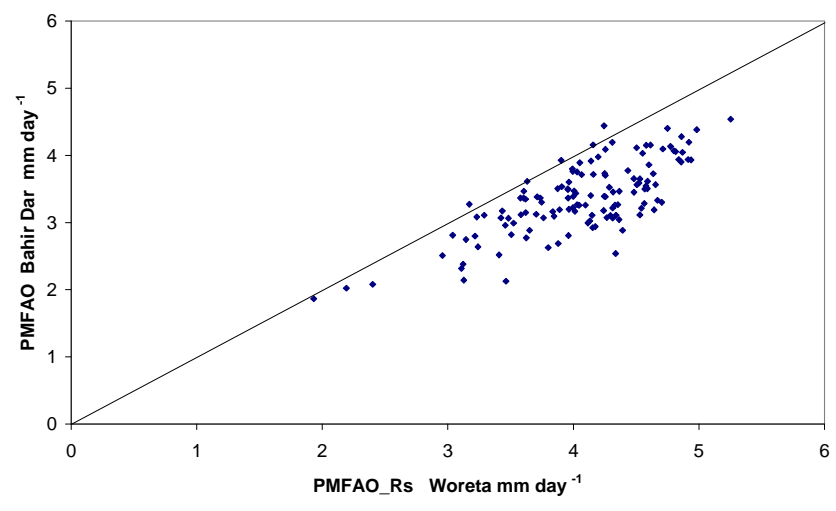

Fig. 7. $\mathrm{ET}_{0}$ measured at Woreta using PMFAO-Rs versus $\mathrm{ET}_{0}$ measured at Bahir Dar using PNFAO with sunshine duration as input. The distance between Bahir Dar and Woreta is about $50 \mathrm{~km}$. Linear regression: slope 0.83 , correlation coefficient 0.74 .

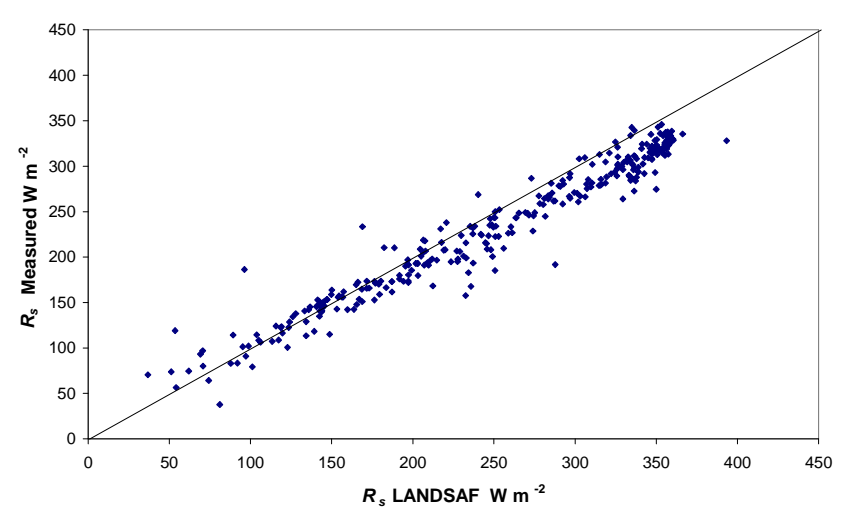

Fig. 8. Comparison measured $R_{\mathrm{S}}$ and the corresponding LANDSAF values for Karameh, Jordan Valley, 2007. Linear regression: slope 0.92 , correlation coefficient 0.97 .

two stations compared well. Apparently, $R_{\mathrm{S}}$ from sunshine duration leads to systematic errors in $\mathrm{ET}_{0}$. It is also possible that this underestimation of $\mathrm{ET}_{0}$ is caused by an underestimation of solar radiation using data of sunshine duration.

In order to test our approach for a region with a significantly different elevation and thus a much higher air pressure, we compared solar radiation and air temperature for 2 sites in the Jordan valley (see Sect. 4). In Fig. 8 the daily measured solar radiation at Karameh is compared with the LANDSAF values for most of 2007. It is seen that the correlation is high, but when $R_{\mathrm{S}}$ exceeds $200 \mathrm{~W} \mathrm{~m}^{-2}$ the LANDSAF data are up to $50 \mathrm{~W} \mathrm{~m}^{-2}$ greater than the measured values. We found similar results for Dair Allah (not shown). There are several reasons that can explain this conditional bias, such as insufficient atmospheric correction due to aerosol scattering.

Figure 9 shows a comparison between spatially interpolated and orographically corrected ECMWF $2 \mathrm{~m}$ temperatures with in situ observations. The correspondence is very good. The results for Dair Allah were again similar. It 


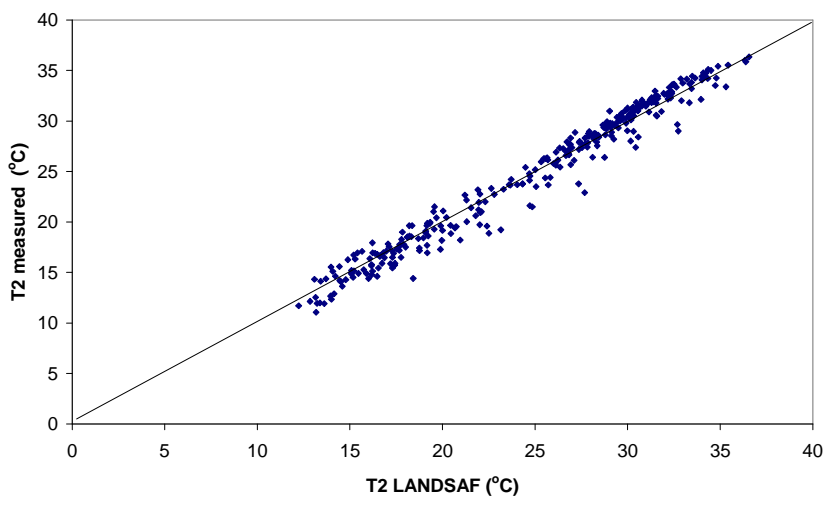

Fig. 9. Comparison measured air temperature (at $2 \mathrm{~m}$ height) and the corresponding LANDSAF values for Karameh, Jordan Valley, 2007. Linear regression: slope 1.00,' correlation coefficient 0.99 .

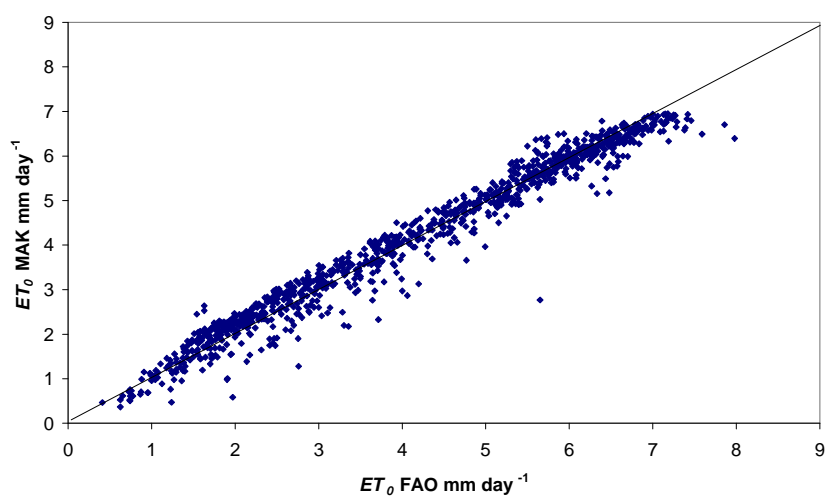

Fig. 10. $E_{0}$ according to PMFAO compared with MAK; Karameh, Jordan Valley, 2007. Linear regression: slope 0.99, correlation coefficient 0.98 .

appeared that MAK performs fairly well, i.e. $\mathrm{ET}_{0}$ as evaluated by NCATT for local applications compare well with MAK (see Fig. 10).

To illustrate the potential availability of the LANDSAF $\mathrm{ET}_{0}$ "product" we show a map of $\mathrm{ET}_{0}$ for Ethiopia and adjacent countries for 15 February 2010. This map is produced just a day before preparing the manuscript of this research note (see Fig. 11).

\section{Discussion and conclusions}

In this case study it is shown that for the Fogera flood plain $\mathrm{ET}_{0}$ determined from LANDSAF solar radiation data and using MAK compares well with the ground truth PMFAORs when the locally measured air temperature is used. This is due to the fact that the MAK performs well in this region. It is noted that the elevation of the experimental site is about 1800, where the mean air pressure is about $82 \mathrm{kPa}$. This reflects in a relative low value for the psychometric constant $\gamma$. In turn this tends to enhance $\mathrm{ET}_{0}$.

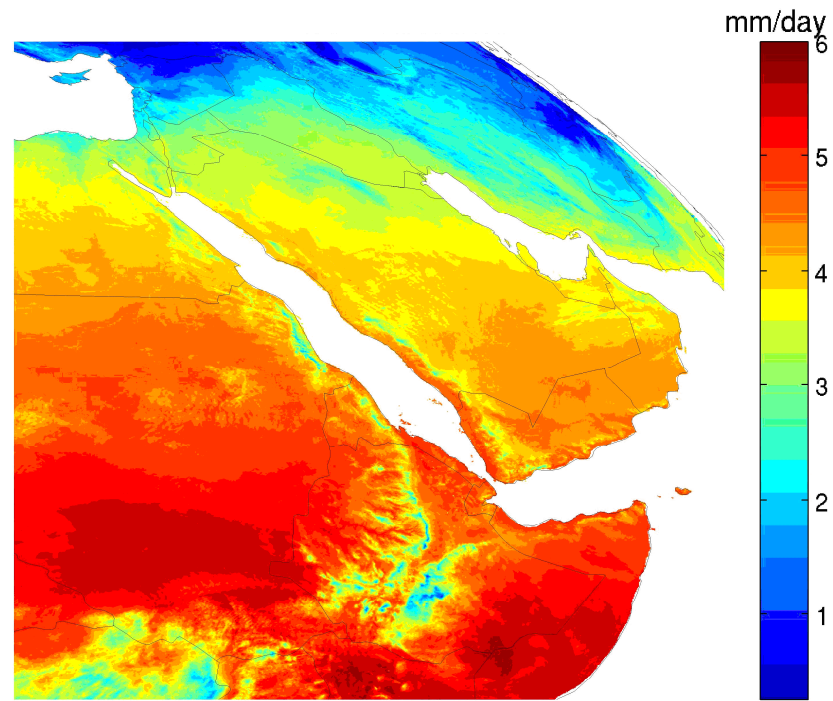

Fig. 11. Example of a LANDSAF $\mathrm{ET}_{0}$ map $\left(\mathrm{mm} \mathrm{d}^{-1}\right)$ covering Ethiopia and Jordan for 15 February 2010.

In this remote region with high elevation the LANDSAFECMWF temperature differs from the observed value. The reason for this underestimate is not known yet. Recently Alemseged (2010) showed that the LANDSAF surface temperature product is useful to estimate temperatures of and near Lake Tana.

Considering the comparison between $\mathrm{ET}_{0}$ determined with PMFAO for two adjacent stations in the region, where at one station $R_{\mathrm{S}}$ is measured directly and at the other evaluated from sunshine duration, and the good quality of the LANDSAF incoming solar radiation product, we tend to conclude that the application of the latter for irrigation practice is advantageous over using locally measured sunshine duration, but we acknowledge that good estimates of solar radiation from sunshine duration are possible provided that they are calibrated locally.

The obvious advantage of the LADSAF $\mathrm{ET}_{0}$ product is that it can be made available almost real-time on MSG-pixel scale for entire Africa and the Middle East.

We recall that PMFAO-Rs is considered the best estimate of $\mathrm{ET}_{0}$ for cases where the input parameters are measured correctly over non-stressed short grass. On purpose, the version of the PMFAO formula where net radiation is observed directly is not taken as a reference. Among others, the reason is that net radiation depends on the actual surface temperature, which plays a part in a complex feedback mechanism with wind speed (De Bruin et al., 2005). For surfaces with an albedo of about $23 \%$ the incoming solar radiation is independent of any surface property, which is an advantage here because $\mathrm{ET}_{0}$ refers to a hypothetical reference surface. In practice, many (if not all) meteorological data are gathered over a (grass) surface suffering soil water stress. What are the consequences? Allen et al. (1998; Annex 6 therein) 
mention the effect on air temperature and humidity, i.e. it is to be expected that in the dry season the air temperature is lower and the humidity above the non-stressed FAO surface higher than over the stressed fields (see also Allen, 1996; Allen et al., 1996). But there are also effects on net radiation. De Bruin (1987) found for a grass site in the Netherlands that the measured net radiation was not representative for nonstressed grass in the extreme dry summer of 1976. Recently, the first author of this paper found for a station in Burkina Faso that in the dry season the measured net radiation over bare soil is significantly smaller than $R_{\mathrm{n}}$ estimates with the empirical formula proposed by De Bruin (1987) for hypothetic non-stressed grass. These findings will be published in a separate paper.

An additional argument not to consider PMFAO with measured net radiation as input as the best approach is the fact that instrumentally net radiation sensors still are not perfect (see e.g. Kustas et al., 1998; Kohsiek et al., 2007).

Internationally, a radiation-temperature based formula for $\mathrm{ET}_{0}$ by Priestley and Taylor (1972), here denoted by PT, is better known (see e.g. Van Kraalingen and Stol, 1997; Utset et al., 2004; Pereira, 2004; Suleiman and Hoogenboom, 2007, 2009):

$\lambda \mathrm{ET}=\alpha \frac{\Delta}{\Delta+\gamma} R_{\mathrm{n}}$

in which $\alpha$ is constant and $R_{\mathrm{n}}$ is the net radiation. The (rounded) value of Priestley-Taylor parameter $\alpha$ is 1.3. For reason mentioned above we think that this approach should be used only above well-watered short grass.

For a grass site in East Netherlands De Bruin and Stricker (2000) confirmed that both PT and MAK give good results under non-stressed conditions. They found that PMFAO appears to be more sensitive to errors in the meteorological input data than MAK. Their explanation is that there is a feedback mechanism between the surface temperature and the wind speed that effectively reduces the influence of wind, at least when the surface is well-watered. This has been confirmed later by De Bruin et al. (2005) for an alfalfa site in Idaho under advective conditions. Because this feedback mechanism is not included in the PMFAO, by choosing a fixed wind-function, PM-FAO is more sensitive to errors in input data. Finally, it is noted that according to the general Penman-Monteith equation evapotranspiration of a surface close to the so-called equilibrium state, i.e. with $\alpha$ close to 1 , is independent of changes in $r_{\mathrm{a}}$ and thus in wind speed (Thom, 1975).

The above arguments justify the application of a formula such as MAK using solar radiation and temperature as input only. In turn, this consideration justifies the use of MAK with solar radiation and temperature provided by the LANDSAF facility. The latter is available for remote regions in Africa and the Middle East.

In conclusion, the LANDSAF-ET 0 approach presented in this research note is very promising, but more work has to be done to test the method under a wider range of environmental conditions. Considering the studies by e.g. Gavilán et al. (2008) and others it is most likely that for more arid and windy regions the Makkink formula tested here has to be adapted. We might come up with different radiationtemperature based LANDSAF-ET 0 estimates for various climatologic classes.

As noted above the authors are well aware of the fact that in arid conditions the MAK tends to underestimate $\mathrm{ET}_{0}$ (Allen et al., 1998; Gavilán et al., 2008; Irmak et al., 2008). In those conditions horizontal advection of sensible heat supplied by the dry upwind terrain tends to enhance evapotranspiration (De Bruin et al., 2005; Berengena and Gavilán, 2005). The physics behind advection is still not solved entirely. Strictly speaking, $\mathrm{ET}_{0}$ is defined for an extensive hypothetical non-stressed grass surface. The La Crau field experiment revealed that close to dry-to-wet step change evaporation decreases fast with height (De Bruin et al., 1991), whereas for very large irrigated alfalfa fields in Idaho the measured ET did not vary much in the first $10 \mathrm{~m}$ above the surface (De Bruin et al., 2004). This implies that under advective conditions the size of the experimental irrigated field plays an important role. Moreover, in highly advective conditions, the sensible heat flux is negative, by which the air is stably stratified. Then the aerodynamic resistance will be smaller than predicted by Eq. (2). Clearly, advection effects on the hypothetical quantity $\mathrm{ET}_{0}$ requires further discussions in the irrigation community. Possibly, it is wise to introduce an advective-free crop reference ET as standard and to describe advection effects separately. In that case the Makkink formula might be an appropriate choice. This topic is outside the scope of this paper.

Another interesting feature of our study is the effect of mean air pressure on $\mathrm{ET}_{0}$ through the psychrometric "constant" $\gamma$, which appears in PMFAO, MAK and PT. At the Ethiopian site $\gamma$ is about $0.055 \mathrm{kPa}^{\circ} \mathrm{C}^{-1}$ and in the Jordan valley $0.066 \mathrm{kPa}^{\circ} \mathrm{C}^{-1}$. This difference is not negligible. Elevation effects on $\mathrm{ET}_{0}$ are reported by Vanderlinden et al. (2008). In this context, it is interesting to note that Delclaux et al. (2008) estimated actual evaporation of Lake Titicaca with an elevation of almost $4 \mathrm{~km}$. They found that MAK was applicable for this lake, provided one accounts for heat storage in the water body. Air pressure effects are not accounted for in other radiation based $\mathrm{ET}_{0}$ estimates such as that by Hargreaves (see Hargreaves and Allen, 2003) or that by Alexandris et al. (2006). We conclude that pressure effect on $\mathrm{ET}_{0}$ needs further investigations.

Acknowledgements. The authors would like to express their gratitude to Mr. Esayas Kaba academic vice dean of Engineering Faculty of Bahir Dar University for his cooperation to use laboratory equipment during the field campaign and for his valuable input during importing field equipment. Mr. Tom Rientjes is acknowledegd for his assistance during the Woreta field experiment. In addition, we like to thank Mr. Ruduwan Mehadi for his cooperation to get meteorological data easily at Bahir Dar. 
This work was carried out within the framework of the Satellite Application Facility on Land Surface Analysis (LSA SAF), funded by EUMETSAT. The authors thanks the directors and members of staff of NCARE who assisted with data collection and processing for the stations in the Jordan Valley. The first author is very grateful to Rick Allen, Pedro Gavilán and Antonio Martínez-Cob for very valuable discussions and for providing him with recent important literature.

Edited by: A. Melesse

\section{References}

Alemseged, B.: Remote sensing of the annual heat storage changes on Lake Tana, Ethiopia, Enschede, MSc thesis ITC, 73 pp., 2010.

Alexandris, S., Kerkides, P., and Liakatas, A.: Daily reference evapotranspiration estimates by the "Copais" approach, Agr. Water Manag., 32, 371-386, 2006.

Allen, R. G.: Assessing integrity of weather data for use in reference evapotranspiration estimation. J. Irrig. Drain. E-ASCE, 122(1), 97-106, 1996.

Allen, R. G., Pereira, L. A., Raes, D., and Smith, M.: Crop evapotranspiration. FAO Irrigation and Drainage Paper 56, FAO, Rome, Italy, 293 pp., 1998.

Allen, R. G., Pruitt, W. O., Businger, J. A., Fritschen, L. J., Jensen, M. E., and Quinn, F. H.: Evaporation and Transpiration, in: ASCE, Handbook of Hydrology, New York, NY, USA, 125-252, 1996.

Berengena, J. and Gavilán, P.: Reference Evapotranspiration Estimation in a Highly Advective Semiarid Environment, J. Irrig. Drain. E-ASCE, 131, 147-163, 2005.

Bois, B., Pieria, P., Van Leeuwen, C., Wald, L., Huard, F., Gaudillere, J.-P., and Saur, E.: Using remotely sensed solar radiation data for reference evapotranspiration estimation at a daily time step, Agr. Forest. Meteorol., 148(4), 619-630, 2007.

Choudhury, B. J. and De Bruin, H. A. R.: First order approach for estimation unstressed transpiration from meteorological satellite data, Adv. Space Res., 16(8), 167-176, 1995.

De Bruin, H. A. R.: From Penman to Makkink, Comm. Hydrol. Res. TNO, Proc. and Inform., Den Haag, 39, 5-30, 1987.

De Bruin, H. A. R., Bink, N. J., and Kroon, L. J. M.: Fluxes in the surface layer under advective conditions, in: Land surface evaporation, edited by: Schmugge, T. J. and André, J. C., 157$171,1991$.

De Bruin, H. A. R., Hartogensis, O. K., Allen, R. G., and Kramer, J. W. J. L.: Note on the Regional Advection Perturbations in an Irrigated Desert (RAPID) Experiment, Theor. Appl. Climatol., 80, 143-152, doi:10.1007/s00704-004-0095-y, 2005.

De Bruin, H. A. R., Moene, A. F., and Bosveld, F. C.: An integrated MSG-scintillometer network system to monitor sensible and latent heat fluxes, in: Proceedings of the Second MSG RAO Workshop 9-10, ESA report SP-582, 2004.

De Bruin, H. A. R. and Stricker, J. N. M.: Evaporation of grass under non-restricted soil moisture conditions, Hydrolog. Sci. J., 45(2), 391-406, 2000.

Delclaux, F., Coudrain, A., and Condom, Th.: Evaporation estimation on Lake Titicaca: a synthesis review and modelling, Hydrol. Process., 21, 1664-1677, 2008.
Fardous, A. A.: Determination of crop coefficients for some direct and indirect methods of estimating evapotranspiration in Jordan Valley, M. Sc. Thesis, University of Jordan, Amman-Jordan, 1983.

Garatuza-Payan, J., Shuttleworth, W. J., Encina, D., McNeil, D. D., Stewart, J. B., De Bruin, H. A. R. and Watts, C. J.: Measurement and modelling evaporation for irrigated crops in north-west Mexico, Hydrol. Process. 12, 1397-1418, 1998.

Garatuza-Payan, J. and Watts, C. J.: Use of remote sensing for estimating ET for NW Mexico, ICID Workshop on Remote Sensing of ET for large Regions, 2003.

Gavilán, P., Estévez, J., and Berengena, J.: Comparison of Standardized Reference Evapotranspiration Equations in Southern Spain, J. Irrig. Drain. E-ASCE, 134, 1-12, 2008.

Geiger, B., Meurey, C., Lajas, D., Franchistéguy, L., Carrer, D., and Roujean, J.-L.: Near real-time provision of downwelling shortwave radiation estimates derived from satellite observations, Meteorol. Appl., 15, 411-420, doi:10.1002/met.84, 2008.

Ghawi, I. O. and Shatanawi, M. R.: Water Consumption of Broad Beans and Beans in the Central Jordan Valley, Damascus University Journal, 10, 11-23, 1986.

Hargreaves, G. H. and Allen, R. G.: History and evaluation of Hargreaves equation, J. Irrig. Drain. E.-ASCE, 129, 53-63, 2003.

Irmak, A., Irmak, S., and Martin, D. L.: Reference and Crop Evapotranspiration in South Central Nebraska, I: Comparison and Analysis of Grass and Alfalfa-Reference Evapotranspiration, J. Irrig. Drain. E.-ASCE, 6, 690-699, 2008.

Jacobs, J. M., Anderson, M. C., Friess, L. C., and Diak, G. R.: Solar radiation, longwave radiation and emergent wetland evapotranspiration estimates from satellite data in Florida, USA, Hydrol. Sci., 49, 461-476, 2004.

Jitan, M. A.: Combining Ground Measurements and Satellite Information For Evaluation of Evapotranspiration and Management of Irrigation in The Jordan Valley, MED-AQUA-2 Conference, Amman-Jordan, 14-15, 2004.

Jitan, M. A.: Evapotranspiration of Major Crops in the Jordan Valley Using Remote Sensing Techniques Compared with Estimated Field Measurement Using Eddy-Correlation, Ph.D. Thesis, University of Jordan, Jordan, 2005.

Kohsiek, W., Liebethal, C., Foken, T., Vogt, R., Oncley, S. P., Bernhofer, C., and De Bruin, H. A. R.: The Energy Balance Experiment EBEX-2000, Part III: Behaviour and quality of the radiation measurements, Bound.-Lay. Meteorol., 123, 55-75, 2007.

Kustas, W. P., Prueger, J. H., Hipps, L. E., Hatfeld, J. L., and Meek, D.: Inconsistencies in net radiation estimates from use of several models of instruments in a desert environment, Agr. Forest Meteorol., 90, 257-263, 1998.

Makkink, G. F.: Testing the Penman formula by means of lysimeters, J. Inst. Water. Env. Man., 11(2), 277-252, 1957.

Mazahreh, N. T.: Evapotranspiration measurement and modeling for Bermuda Grass, Alfalfa, Cucumber, and tomato under protected cultivation in the central Jordan valley, $\mathrm{PhD}$. Thesis, University of Jordan, Amman, Jordan, 2001.

Pereira, A. R.: The Priestley-Taylor parameter and the decoupling factor for estimating reference evapotranspiration, Agr. Forest Meteorol., 125, 305-313, 2004.

Priestley, C. H. B. and Taylor, R. J.: On the assessment of surface heat flux and evaporation using large scale parameters, Mon. Weather Rev., 100, 81-92, 1972. 
Schillings, C., Mannstein, H., and Meyer, R.: Operational method for deriving high resolution solar direct normal irradiance from satellite data, Sol. Energy, 76, 475-484, 2004.

Schüttemeyer, D.: The surface energy balance over drying semiarid terrain in West Africa, Ph.D. Thesis Wageningen University, 154 pp., 2005.

Schüttemeyer, D., Schillings, C., Moene, A. F., and De Bruin, H. A. R.: Satellite-based actual evapotranspiration over drying semiarid terrain in West Africa, J. Appl. Meteorol. Clim., 46, 97-111, 2007.

Shatanawi, M. R., Ghawi, I., Fayyad, M., Habbab, M., Taimeh, A., Abu Awwad, A., Wolf, J., Gleason, J., Salti, S., Ababneh, M., Jitan, M., and Hamdan, M.: Irrigation management and water quality in the central Jordan valley, a baseline report prepared for the USAID mission to Jordan, prepared by the water and environment research and study center, University of Jordan, AmmanJordan, Jordan, 1994.

Shatanawi, M. R., Ghawi, I., and Sharaiha, R. : Actual consumptive use of wheat and barely in the Jordan Valley, Dirasat, Deanship of Academic Research, University of Jordan, Amman, http://dar. ju.edu.jo/dirasatonline, last access: November 2010, 14(1), 4967, 1986.

Sinclair, S. and Pegram, G. G. S.: A comparison of ASCAT and modelled soil moisture over South Africa, using TOPKAPI in land surface mode, Hydrol. Earth Syst. Sci., 14, 613-626, doi:10.5194/hess-14-613-2010, 2010.

Stewart, J. B., Watts, C. J., Rodriguez, J. C., De Bruin, H. A. R., Van den Berg, A. R., and Garatuza-Payán, J.: Use of satellite data to estimate radiation and evaporation for north-west Mexico, Agr. Water Manage., 38, 181-193, 1999.

Suleiman, A. and Hoogenboom, G.: Comparison of PriestleyTaylor and FAO-56 Penman-Monteith for Daily Reference Evapotranspiration Estimation in Georgia, J. Irrig. Drain. E-ASCE, 133(1), 175-182, 2007.
Suleiman, A. and Hoogenboom, G.: A comparison of ASCE and FAO-56 reference evapotranspiration for a 15 -min time step in humid climate conditions, J. Hydrol., 375, 326-333, 2009.

Temesgen Enku, N.: Estimation of evaporation from satellite remote sensing and meteorological data over the Fogera flood plain, Ethiopia, MSc thesis ITC, Enschede, 89 pp., 2009.

Thom, A. S.: Momentum, Mass and Heat Exchange of Plant Communities, in: Vegetation and the atmosphere: principles, edited by: Monteith, J. L., Academic Press, 57-111, 1975.

Trigo, I. F., DaCamara, C. C., Viterbo, P., Roujean, J.-L., Olesen, F., Barroso, C., Camacho-de Coca, F., Carrer, D., Freitas, S. C., García-Haro, J., Geiger, B., Gellens-Meulenberghs, F., Ghilain, N., Meliá, J., Pessanha, L., Siljamo, N., and Arboleda, A.: The Satellite Application Facility on Land Surface Analysis, Int. J. Remote Sens., in press, doi:10.1080/01431161003743199, 2010.

Utset, A., Farré, I., Martínez-Cob, A., and Cavero, J.: Comparing Penman-Monteith and Priestley-Taylor approaches as referenceevapotranspiration input for modeling maize water use under Mediterranean conditions, Agr. Water Manage., 66, 205-219, 2004.

Vanderlinden, K., Girádez, J. V., and Van Meirvenne, M.: Spatial Estimation of Reference Evapotranspiration in Andalusia, Spain, J. Hydrometeorol., 9, 242-255, 2008.

Van Kraalingen, D. W. G. and Stol, W.: Evapotranspiration Modules for Crop Growth Simulation, Quantities Approaches in System analysis, Vol. 11, 29 pp., 1997.

Watts, C. J., Rodríguez, J. C., Payán, J. G., De Bruin, H. A. R., and Stewart, J.: Estimación de evaporación y radiación solar en el valle del Yaqui, Sonora, usando datos de satélite, Ingeniería Hidráulica en México, 14, 45-53, 2000. 